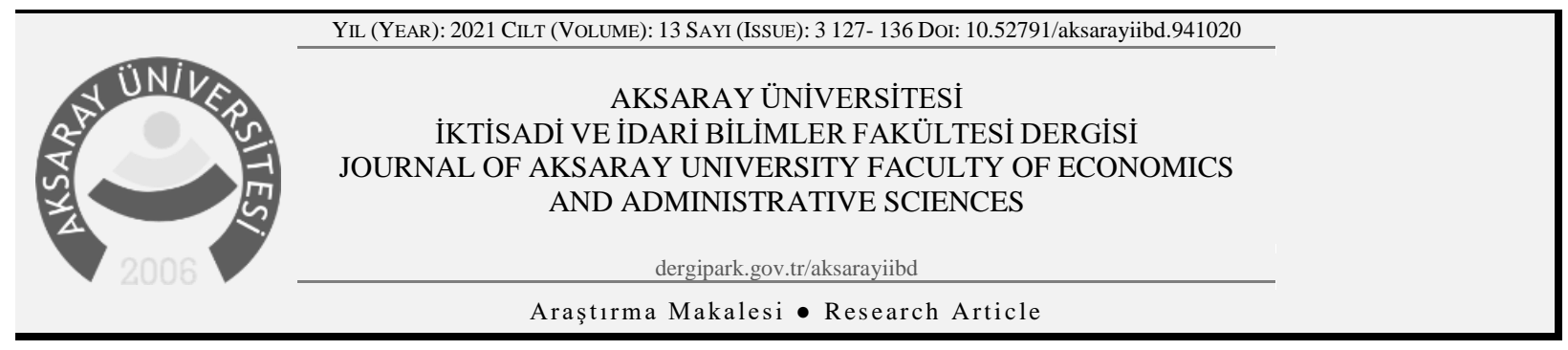

\title{
Sanayi Sektöründe İhracatın İstihdama Etkisi: Türkiye İçin Asimetrik Nedensellik Testi
}

\author{
The Impact of Export on Employment in Industry Sector: Asymmetric Causality Test for \\ Turkey
}

\author{
Mustafa Gerçeker ${ }^{1}$ \\ ${ }^{\text {ID }}$ r. Öğretim Üyesi,, Selçuk Üniversitesi, İktisadi ve İdari Bilimler Fakültesi, İktisat Bölümü, mustafagerceker@selcuk.edu.tr, Orcid Id: \\ 0000-0002-2920-255X
}

M A K A L E B İ L G İ S I

Anahtar Kelimeler

Ihracat,

Istihdam,

Fourier Birim Kök Testi,

Asimetrik Nedensellik Testi

\section{Makale Geçmiși}

Geliş Tarihi: 22 Mayıs 2021

Kabul Tarihi: 4 Eylül 2021.

A R T I C LE IN F O

\section{Keywords}

Export,

Import,

Fourier Unit Root Test, Asymmetric Causality Test

\section{Article History:}

Received: 22 May 2021

Accepted: 4 September 2021
Ö ZE T

Dünya ekonomisinde 1980'li yıllarda başlayan ticari liberalizasyon süreciyle birlikte gelişmekte olan ülkeler ithal ikameci sanayileşme politikalarını terk etmiş ve ihracata yönelik büyüme stratejisini benimsemişlerdir. Diş ticaretteki bu strateji değişikliğinden sonra ülkeler için önemi oldukça artan ihracatın, çeşitli makro ekonomik göstergelere olan etkisi de araştırmacılar açısından merak konusu olmuştur. Gelişmekte olan ülkelerin pek çoğunda olduğu gibi Türkiye ekonomisinde de benzer bir süreç yaşanmıştır. Türkiye'nin 1980 yılında yaklaşık 3 milyar dolar düzeyinde olan ihracatı, 2020 yılında 170 milyar dolar seviyesine kadar yükselmiştir. Türkiye toplam ihracatının yüzde doksanından fazlası ise sanayi sektörü tarafindan gerçekleştirilmektedir. Bu çalışmada Türkiye'nin sanayi sektöründeki ihracat ve istihdam ilişkisi 1991-2019 dönemi için ampirik olarak incelenmiștir. Çalışmada kullanılan veriler Dünya Bankası veri tabanından temin edilmiştir. Ampirik yöntem olarak Fourier tabanlı FKPSS ve FADF birim kök testleri ile Hatemi-J (2011) Asimetrik Nedensellik Testi tercih edilmiştir. Birim kök testinden elde edilen bulgular serilerin birinci farklarında durağan olduklarını göstermektedir. Asimetrik nedensellik testi sonuçları ise "ihracata ilişkin pozitif şoklar istihdamda ortaya çıkan pozitif şokların nedeni değildir" ve "ihracata ilişkin negatif şoklar istihdamda ortaya çıkan negatif şokların nedeni değildir" hipotezleri reddedilmektedir. Buna göre ihracattaki artış veya azalışlar, istihdamda ortaya çıkan aynı yönlü değişimlerin nedeni olarak kabul edilmektedir.

\section{A B S T R A C T}

With the commercial liberalization process that started in the world economy in the 1980s, developing countries abandoned their import substitution industrialization policies and adopted an export-oriented growth strategy. The effect of export, which has become very important for countries after this change in strategy in foreign trade, on various macroeconomic indicators has also been a matter of curiosity for researchers. As in many developing countries, it has experienced a similar process in Turkey's economy. Turkey's exports to nearly $\$ 3$ billion in 1980, rose in 2020 to 170 billion dollars. and more than ninety percent of Turkey's total exports are carried out by the industrial sector. In this study, Turkey's exports and employment in the industrial sector for the 1991-2019 period were examined empirically. The data used in the study were obtained from the World Bank database. Fourier-based FKPSS and FADF unit root tests and Hatemi-J (2011) Asymmetric Causality Test were preferred as empirical methods. The findings obtained from the unit root test show that the first differences of the series are stationary. Asymmetric causality test results are rejected with the hypotheses that "positive shocks related to exports are not the cause of positive shocks in employment" and "negative shocks related to exports are not the cause of negative shocks in employment" are rejected. Accordingly, increases or decreases in exports are accepted as the cause of the same directional changes in employment. 
eoklasik iktisatçılar kısa dönemde ekonomik faaliyet seviyesinin ve buna bağlı olarak istihdam düzeyinin hem makro $\mathrm{N}$ değişkenlerden (para arzı, faiz oranları vs.) hem de diş ticaret politikasındaki dalgalanmalardan (veya ticaret şoklarından) etkilenebileceğini savunmaktadır. Ancak uzun dönemde diş ticaret politikasından ziyade makroekonomik gelişmeler ve işgücü piyasası olguları (işgücü arzı, işgücü talebi, ücret düzeyi vs.) işsizlik ve istihdam üzerinde daha belirleyici bir konum üstlenmektedir (Hoekman ve Winters, 2005: 2). Ticaretin serbestleşmesiyle beraber ihracat sektöründe talep edilen işgücü ile ithal ikameci sektörde talep edilen işgücü arasında ise niteliksel açıdan farklılıklar ortaya çıkmaktadır. İşgücü talebindeki bu yeni durum, genellikle ücret değişikliklerini ve göreli gelir farklılıklarını da beraberinde getirmektedir. $\mathrm{Bu}$ bağlamda geleneksel ticaret modelleri, ticaretin, istihdam düzeyini etkilemediğini savunmasına rağmen; ücret değişmeleri nedeniyle bazı işçilerin uzun vadede daha iyi (veya daha kötü) durumda olabileceğini ileri sürmektedir (Jansen ve Lee, 2007: 25). Ayrıca geleneksel ticaret modelleri, ticaretin, emek faktörü de dahil olmak üzere kaynakların sektörel dağılımını değiştirdiğine dikkat çekerek, ticaret ve istihdam ilişkisinin bazı kanallar üzerinden işleyebileceğine dikkat çekmektedir Bu noktada önemli bir kanal; ticaret ve ekonomik büyüme arasındaki ilişki olmaktadır. Eğer ticari açıklığın büyüme üzerinde olumlu bir etkisi varsa, yurt içinde daha fazla mal ve hizmet üretilebileceğinden dolayı istihdamın artması beklenilebilir (UNCTAD, 2018: 16). Ancak Heckscher-Ohlin teoreminin de varsayımları arasında yer alan "tam istihdam" görüşüne dayalı olarak klasik ve neoklasik perspektifte ticaret ve istihdam arasında uzun dönemde doğrudan etkileşim olmadığı sonucu çıkarılabilir.

Öte yandan kısa dönem açısından ele alındığı takdirde uluslararası ticaret ve istihdam arasındaki ilişki; ölçek etkisi ve ikamet etkisi yaklaşımları çerçevesinde açıklanmaktadır. Ölçek etkisi yaklaşımı; "dışa açılan bir ülkenin uluslararası ticarete entegrasyonu ne ölçüde büyük olursa, ihracata yönelik faaliyet gösteren sektörlerdeki üretimin de o ölçüde büyük olacağını ve buna bağlı olarak da yüksek bir işgücü talebi oluşacağını” ifade etmektedir. Buna karşılık ikame etkisi yaklaşımında ise; "uluslararası ticaretteki artışa bağlı olarak yerli üretimin ithal mallar ile ikame edilmesine neden olacağına ve bunun sonucunda da ithal ikameci üretim gerçekleştiren sektörlerde istihdamda azalma gerçekleşeceğine" dikkat çekilmektedir (Ha ve Tran, 2017: 532). Burada iki etki bir arada değerlendirildiğinde; basit Heckscher-Ohlin-Samuelson modelinin çizdiği çerçeveye göre istihdamın, ithal ikameci sektörden, ihraç mallar üreten sektöre doğru yeniden bir dağılıma neden olduğu şeklinde bir yorum da yapılabilir (Greenaway vd., 1999: 488). Tam istihdam varsayımını fazla gerçekçi bulmayan yeni dış ticaret teorilerine dayalı tezler dikkate alındığında; ticaret ve istihdam arasında var olduğu düşünülen bağlantı, ulusal ve uluslararası düzeyde ticaret politikasının ön planda tutulduğu mevcut küresel ekonomik konjonktürde büyük önem taşımaktadır. Bu bağlamda ticaretin istihdam üzerindeki etkisi araştırılması gereken önemli konulardan biri haline gelmektedir (Kutlina-Dimitrova vd., 2018: 2). Ekonomi eksik istihdam durumundayken gerçekleştirilen bir ticaret reformuna veya serbestleştirme politikasına bağlı olarak ihracat sektörü için gerekli işgücü talebi, mevcut ücret koşullarında istihdamın dışında kalan işgücü arzı tarafından karşılanıyorsa ihracatın kayıtlı istihdamı artırması mümkündür. Diğer yandan görece yüksek asgari ücret imkanlarına sahip düşük vasıflı işgücünün ağırlıklı olarak ithal ikameci sektörde faaliyet gösterdiği koşullarda gerçekleştirilen ticaret reformu veya serbestleştirme sonucunda; ihracat sektörünün ihtiyacını karşılayamayan bu düşük vasıflı işçilere talep azalacak ve yapısal işsizlik durumu söz konusu olabilecektir (Jansen ve Lee, 2007: 26). Ticaret politikalarındaki değişime bağlı olarak ortaya çıkan değişimlere uyum sağlama süresinin uzun olması ise işsizlik üzerinde oldukça belirleyici olacaktır (Thompson vd., 2012: 115). Ancak mevcut yapının değişmediği koşullarda ihracat sektöründeki genişleme istihdam artışıyla sonuçlanabilir. Ortaya atılan teorik çıkarsamaların ve tartışmaların 1şı̆̆ında; gelişmiş ülkelerin yanı sıra 1980 sonrası ithal ikameci sanayileşme politikaları yerine ihracata dayalı büyüme modelini benimseyen gelişmekte olan ülkeler için özellikle ihracatın istihdama olan etkisi akademik düzeyde faaliyet gösteren araştırmacıların ilgisini kazanmıştır. Buradan hareketle Türkiye ekonomisi için imalat sanayi alanındaki ihracata yönelik gelişmelerin sanayi istihdamı üzerine olan etkisini belirlemek, bu çalışmanın amacını oluşturmaktadır. Tablo 1'de, Türkiye'nin 1980 sonrası temel diş ticaret göstergelerindeki gelişmelere ilişkin rakamsal bilgiler gösterilmektedir. 1980 yılında başlayan ihracata yönelik sanayileşme ve liberalizasyon süreciyle beraber Türkiye ekonomisinde dış ticaretin önemi hızla artmıştır. Türkiye'nin ihracatı 1980 yılında 2,9 milyar dolar iken 2020 yılında bu rakam 169,6 milyar dolara ulaşmıştır. Diğer yandan ithalatta da benzer bir tablo ortaya çıkmıştır. Buna göre 1980 yılında 7.9 milyar dolar değerinde ithalat yapan Türkiye, 2020 y1lında gelindiğinde 219,5 milyar dolarlık ithalat gerçekleştirmiştir. Ele alınan tüm dönemler için Türkiye ekonomisi dış ticaret açı ğ1 vermekte ve buna bağlı olarak ihracatın ithalatı karşılama oranı \% 100’ün altında seyretmektedir. 
Tablo 1. Türkiye Ekonomisi Temel Dış Ticaret Göstergeleri (1980-2020)

\begin{tabular}{|c|c|c|c|c|c|}
\hline Yillar & İhracat* & Ithalat* & Dış Ticaret Dengesi* & Dış Ticaret Hacmi* & $\begin{array}{c}\text { İhracatın İthalatı Karşılama } \\
\text { Oranı }(\%) \\
\end{array}$ \\
\hline 1980 & 2910 & 7909 & -4999 & 10819 & 36,8 \\
\hline 1985 & 7958 & 11343 & -3385 & 19301 & 70,2 \\
\hline 1990 & 12959 & 22302 & -9342 & 35261 & 58,1 \\
\hline 1995 & 21637 & 35709 & -14071 & 57346 & 60,6 \\
\hline 2000 & 27774 & 54502 & -26727 & 82277 & 51,0 \\
\hline 2005 & 73476 & 116774 & -43297 & 190250 & 62,9 \\
\hline 2010 & 113883 & 185544 & -71661 & 299427 & 61,4 \\
\hline 2011 & 134907 & 240842 & -105.935 & 375.749 & 56,0 \\
\hline 2012 & 152462 & 236546 & -84.084 & 389.007 & 64,4 \\
\hline 2013 & 161481 & 260823 & -99342 & 422304 & 61,9 \\
\hline 2014 & 166505 & 251143 & -84638 & 417648 & 66,3 \\
\hline 2015 & 150983 & 213620 & -62638 & 364602 & 70,7 \\
\hline 2016 & 149247 & 202190 & -52943 & 351437 & 73,8 \\
\hline 2017 & 164495 & 238716 & -74221 & 403210 & 68,9 \\
\hline 2018 & 177169 & 231153 & -53984 & 408322 & 76,6 \\
\hline 2019 & 180833 & 210346 & -29513 & 391178 & 86,0 \\
\hline 2020 & 169670 & 219510 & -49841 & 389180 & 77,3 \\
\hline
\end{tabular}

* milyon ABD doları

Kaynak: TÜİK

Tablo 2, ISIC Rev 3 sınıflaması Düzey 1'e göre 2020 yılında Türkiye'nin dış ticaretindeki sektörel rakamları ve yüzde cinsinden payları göstermektedir. Bu bilgilere göre; Türkiye toplam ihracatının yaklaşı olarak \%93,75'lik kısmı; toplam ithalatın da yaklaşık \%80'lik kısmı imalat sanayi alanında gerçekleştirilmektedir.

Tablo 2. ISIC Rev3 Sınıflamasına Göre Dış Ticaret (Düzey 1) - (2020 yılı)*

\begin{tabular}{|l|c|c|c|}
\hline \multicolumn{1}{|c|}{ ISIC adı } & İhracat & $(\boldsymbol{\%})$ & İthalat \\
\hline Tarım ve Ormancılık & 5.878 .849 .733 & 3,6585 & 9.626 .569 .027 \\
\hline Balıkçılık & 556.341 .254 & 0,3462 & 3,5943 \\
\hline Madencilik ve Taşocakçılığı & 2.943 .212 .025 & 1,8316 & 22.337 .324 .313 \\
\hline İmalat Sanayi & 150.646 .697 .822 & 93,7505 & 169.387 .111 .564 \\
\hline Elektrik, Gaz ve Su & 81.810 .346 & 0,0509 & 50,8606 \\
\hline Toptan ve Perakende Ticaret & 569.032 .345 & 0,3541 & 8.032 .553 .048 \\
\hline Gayrimenkul, Kiralama ve İş Faaliyetleri & 132.124 & 0,0001 & 271 \\
\hline Diğger Sosyal, Toplumsal ve Kişisel Hizmetler & 12.946 .705 & 0,0265 & 278.674 \\
\hline
\end{tabular}

* 2020 yılına ilisskin revize edilmemiş rakamlar yer almaktadır.

Kaynak: TÜİK

Tablo 3, ekonomik faaliyet alanına göre 2020 yılı Kasım ayına ilişkin Türkiye'de istihdam edilen kişi sayısını ve sektörlerin oransal payını göstermektedir. Bu verilere göre; Türkiye'de toplam 26 milyon 728 bin kişi istihdam edilmektedir. İstihdam edilenlerin \%56,4'ü hizmet sektöründe, \%20,9'u sanayi sektöründe, $\% 16,4$ 'ü tarım sektöründe ve \%6,3'ü de inşaat sektöründe faaliyet göstermektedir.

Tablo 3. Ekonomik Faaliyete Göre 15 yaş üstü İstihdam Edilenler (2020 Kasım) (bin kişi)

\begin{tabular}{|c|c|c|c|c|c|c|c|}
\hline Tarım & \% & Sanayi & \% & Inşaat & \% & Hizmet & Toplam \\
\hline 4382 & 16,4 & 5588 & 20,9 & 1682 & 6,3 & 15077 & 56,4 \\
\hline
\end{tabular}

Kaynak: TÜíK

Çalışma dört ana başlıktan oluşmaktadır. İlk bölümde ihracat ve istihdam ilişkisinin teorik çerçevesi ve Türkiye'deki duruma ilişkin rakamsal bilgiler giriş kapsamında sunulmaktadır. Türkiye ve diğer ülke (veya ülke grubu) örneklemleri üzerine ihracat ve istihdam ilişkisini ampirik olarak inceleyen literatüre dair özet bilgiler ikinci bölümde yer almaktadır. Üçüncü bölüm, çalışmanın ampirik testleri için kullanılan veri seti, yöntem ve ampirik bulgulardan oluşmaktadır. Dördüncü ve son bölümde ise çalışmanın ampirik bulguları doğrultusunda ulaşılan sonuca ilişkin açıklamalar verilmektedir.

\section{AMPIRIKK LITERATÜR}

Literatür taraması, ekonometrik modeli içerisinde ihracat ve istihdam (veya işsizlik) değişkenlerine yer veren çalışmaları kapsamaktadır. Genel bir değerlendirme yapıldığı takdirde ticaret ve istihdam ilişkisini ele alan çalışmalarda en sık başvurulan yöntemin katsayı tahmini olduğu görülmektedir. Katsayı tahmini veya diğer yöntemlerle yapılan söz konusu çalışmaların çoğunda ihracatın, istihdama pozitif katkıda bulunduğu sonucu dikkat çekmektedir. Türkiye örnekleminde ve diğer ülke (veya ülke grubu) örneklemleri üzerine yapılmış çalışmaların bir bölümü aşağıda yer alan tablolarda ayrı ayrı sunulmuştur. 
Tablo 4. Diğer Ülke (veya ülke grubu) Örneklemi İçin Seçilmiş Literatür Özeti

\begin{tabular}{|c|c|c|c|}
\hline Yazar(lar) & Örneklem & Dönem & Yöntem \\
\hline Abbey vd. (2017) & Gana & $2013-2015$ & Katsayı Tahmini \\
\hline Chen vd. (2012) & Çin & $2002-2007$ & Girdi-Çıktı Analizi \\
\hline Dizaji ve Badri (2014) & İran & $1976-2005$ & ARDL Katsayı Tahmini \\
\hline Feenstra vd. (2019) & ABD & $1991-2011$ & Katsayı Tahmini \\
\hline Fu ve Balasubramanyam (2005) & Çin (29 ildeki kasaba ve köy işletmeleri) & $1987-1998$ & Panel GMM Katsayı Tahmini \\
\hline Görg ve Görlich (2011) & Almanya & $1999-2007$ & Regresyon Analizi \\
\hline Greenaway vd. (1999) & Birleşik Krallık (167 imalat sektörü için) & $1979-1991$ & Panel Katsayı Tahmini \\
\hline Gül ve Kamacı (2012) & Gelişmiş 12 ülke ve Gelişmekte Olan 7 ülke & $\begin{array}{c}1980-2010 \text { (GÜ) } \\
1993-2010 \text { (GOÜ) }\end{array}$ & Panel Granger Nedensellik \\
\hline Hisali (2011) & Uganda & 1994Q1-2009Q4 & Johansen Eşbütünleşme ve Katsayı Tahmini \\
\hline Kien ve Heo (2009) & Vietnam & $1999-2004$ & SYS-GMM Tahmin Metodu \\
\hline Leichenko (2000) & ABD (4 Bölge) & 1980-1991 & Granger Nedensellik Testi \\
\hline Nguyen (2015) & Vietnam & $2000-2007$ & Girdi-Çıktı Analizi \\
\hline Sasahara (2019) & ABD, Çin ve Japonya & $2000-2014$ & Girdi-Çıktı Analizi \\
\hline Tuhin (2015) & Avusturalya & $1969-2012$ & Katsayı Tahmini \\
\hline Whang (2019) & Güney Kore & $1980-2010$ & Arrelano-Bond (1991) GMM Tahmin Metodu \\
\hline
\end{tabular}

Tablo 4'te sunulan diğer ülke (veya ülke grubu) örneklemi üzerine ampirik yöntemler kullanılarak gerçekleştirilen çalışmalardan Abbey vd.(2017), Chen vd.(2012), Dizaji ve Badri (2014), Feenstra vd.(2019), Fu ve Balasubramanyam (2005), Hisali (2011), Kien ve Heo (2009), Nguyen (2015) ve Tuhin (2015) ihracatın, istihdamı pozitif etkilediği bulgusunu elde etmişlerdir. Sasahara (2019), ABD, Çin ve Japonya üzerine yapmış olduğu çalışmada her bir ülkede ihracatın, istihdama pozitif katkıda bulunduğuna işaret etmekle beraber bu katkının sektörel bazda farklılaştığını, katma değeri yüksek sektörlerde istihdama katkının da yüksek olduğunu belirtmektedir. Whang (2019)'da ihracatın istihdama pozitif katkıda bulunduğunu ancak bu katkının ihracat sektörünün üretim tekniğine ve büyüklüğüne bağlı olarak değişebileceğini ifade etmektedir. Bu bağlamda Whang, sermaye-yoğun tekniğin daha ön planda olduğu bir imalat sektöründeki ihracat artışının istihdama katkısının daha sınırlı olduğunu işaret etmektedir. Diğer yandan Greenway vd. (1999) ise ihracatın istihdamı negatif etkilediği bulgusunu elde etmiştir. Buna benzer bir sonuç ise Görg ve Görlich (2011) tarafindan Almanya üzerine yapılmış çalışmada elde edilerek, hizmet sektörü ihracatı ile istihdam arasında negatif yönlü bir ilişki olduğu belirtilmiştir. Tablo 4'te yer alan çalışmalardan Gül ve Kamacı (2012) ile Leichenko (2000) çalışmalarında ampirik yöntem olarak Granger Nedensellik Testi uygulandığ 1 dikkat çekmektedir. Gül ve Kamacı (2012) ele aldığı her iki ülke grubu açısından da ihracattan işsizliğe (istihdama) doğru tek yönlü nedensellik olduğu bulgusunu elde etmişlerdir. Leichenko (2000) ise ABD'nin dört bölgesi üzerine gerçekleştirdiği çalışmasında Kuzeydoğu ve Batı bölgeleri için ihracat ve istihdam arasında çift yönlü nedensel ilişkinin olduğu sonucuna ulaşmıştır.

Tablo 5. Türkiye Örneklemi İçin Seçilmiş Literatür Özeti

\begin{tabular}{|c|c|c|c|}
\hline Yazar(lar) & Örneklem & Dönem & Yöntem \\
\hline Akkuş (2014) & Türkiye & $2003-2010$ & Panel (Sabit Etkiler) Regresyon \\
\hline Akkuş (2019) & $\begin{array}{c}\text { Türkiye } \\
\text { (22 İmalat Sektörü) } \\
\end{array}$ & 2009-2017 & $\begin{array}{c}\text { (Panel Veri) İki Aşamalı En Küçük Kareler } \\
\text { Yöntemi }\end{array}$ \\
\hline Aktakaş vd. (2013) & Türkiye & $2004-2011$ & Panel En Küçük Kareler \\
\hline Altay ve Y1lmaz (2016) & Türkiye & 2005:M1-2015:M9 & FMOLS Katsayı Tahmini \\
\hline Altuntepe (2018) & Karabük ili & 2006:M1-2017:M12 & $\begin{array}{l}\text { VAR Analizi, Etki-Tepki Analizi, Varyans } \\
\text { Ayrıştırma }\end{array}$ \\
\hline Avşar ve Onaran (2010) & Türkiye & 1973-2001 & Katsayı Tahmini \\
\hline Ayhan (2018) & Türkiye & 2005:M1-2014:M2 & ARDL Katsay1 Tahmini \\
\hline Çütcü ve Cenger (2017) & Türkiye & 2005:M1-2017:M3 & $\begin{array}{l}\text { Gregory-Hansen Eşbütünleşme Testi, } \\
\text { Toda-Yamamoto Nedensellik Testi }\end{array}$ \\
\hline Ersin ve Ergeç (2018) & Türkiye & 2000:Q1-2016:Q4 & Toda Yamamoto Nedensellik Testi \\
\hline Göçer vd. (2013) & Türkiye & 2000:Q1-2011:Q1 & ARDL Katsayı Tahmini \\
\hline Karaçor ve Saraç (2011) & Türkiye & $1963-2009$ & ARDL Katsayı Tahmini \\
\hline Kizılırmak (2012) & $\begin{array}{c}\text { Türkiye } \\
\text { (71 İmalat Sektörü) }\end{array}$ & 1989-2004 & Regresyon Analizi \\
\hline Polat vd. (2011) & $\begin{array}{c}\text { Türkiye } \\
\text { (22 İmalat Sektörü) }\end{array}$ & 2003-2008 & Panel En Küçük Kareler \\
\hline Tandoğan (2019) & $\begin{array}{c}\text { Türkiye } \\
\text { (Düzey 2- Bölgesel) }\end{array}$ & 2005-2016 & Panel Katsayı Tahmini \\
\hline Yıldız ve Akduğan (2014) & Türkiye & $\begin{array}{l}1923-1979 \\
1980-2013\end{array}$ & Toda Yamamoto Nedensellik Testi \\
\hline
\end{tabular}

Türkiye örneklemi için gerçekleştirilen çalışmalardan Akkuş (2014; 2019), Altay ve Y1lmaz (2016), Ayhan (2018), Göçer vd. (2013), Karaçor ve Saraç (2011) ve Tandoğan (2019), ihracatın istihdama pozitif katkıda bulunduğuna işaret etmektedir. Avşar ve Onaran (2010) ise ihracatın istihdama pozitif katkıda bulunduğunu ancak bu katkının zayıf olduğunu belirtmektedir. Aktakaş vd. (2013) çalışmasında statik analiz sonuçlarından elde edilen bulgular sektörel ihracat ve sektörel istihdam 
arasında pozitif bir ilişki olduğunu, dinamik analiz sonuçlarından elde edilen bulgular ise negatif ilişki olduğunu göstermektedir. Literatürde kısa ve uzun döneme göre farklı sonuçlar veren çalışmalar da yer almaktadır. Bu çalışmalardan Altuntepe (2018) ihracatın kısa dönemde istihdamı pozitif etkilediği, uzun dönemde ise etkide bulunmadığını bildirirken; Kızılırmak (2012) ihracatın kısa dönemde istihdamı olumsuz etkilediğini, uzun dönemde ise pozitif etkilediğini belirtmektedir. Diğer yandan Polat vd. (2011) ihracatın, istihdam üzerinde anlamlı bir etkide bulunmadığına işaret etmektedir. Tablo 5 'te yer alan çalışmalardan üç tanesinde nedensellik testi uygulanmıştır ve söz konusu bu üç çalışmada da Toda-Yamamoto Nedensellik yöntemi tercih edilmiştir. Bu çalışmalardan Cütcü ve Cenger (2017) ve Yıldız ve Akduğan (2014) ihracat ve istihdam arasında nedensel bağıntı olmadığı bulgusunu elde etmişlerdir. Sektörel bazda ampirik analiz gerçekleştirilen Ersin ve Ergeç (2018), tüm sektörlerin toplam istihdamı, sanayi sektörü istihdamı, tarım sektörü istihdamı ve hizmet sektörü istihdamından ihracata doğru olmak üzere tek yönlü nedensel bağıntı olduğu; inşaat sektörü istihdamı ve ihracat arasında ise çift yönlü nedensellik olduğu sonucunu elde etmişlerdir.

\section{VERİ, YÖNTEM VE AMPIRIKK BULGULAR}

İhracat ve istihdam ilişkisinin ampirik olarak incelendiği geçmiş çalışmalarda; belli bir miktar ihracat ürününü üretmek için gereken işgücü miktarının hesaplanabildiği faktör içeriği analizi, istihdamdaki değişmenin kaynaklarının yurtiçi talep, dış ticaret ve üretkenlik öğelerine ayrıştırılmasına olanak sağlayan büyüme muhasebesi yöntemi ve dolaylı etkilerin de tahmin edilmesine imkan veren regresyon yöntemleri uygulanmıştır (Kızılırmak, 2012: 1). Zamanla güncel ekonometrik testler kullanılarak ihracat ve istihdam ilişkisinin ampirik literatürü genişlemiştir. Bu çalışmada ampirik yöntem olarak; Fourier tabanlı FADF (Enders ve Lee, 2012) ve FKPSS (Becker vd. 2006) birim kök testleri ile Toda-Yamamato tabanlı Hatemi-J (2011) asimetrik nedensellik testi uygulanmıştır. Türkiye'de imalat sanayi ihracatı (Y) ve sanayi istihdamı (X) arasındaki ilişkiyi test etmek amacıyla yapılan ekonometrik analiz için gerekli olan veriler ise Dünya Bankası veri tabanından temin edilmiştir. Analize tabi tutulan veriler, 1991-2019 dönemini kapsamaktadır. Değişkenlere ilişkin tanımlayıcı istatistikler Tablo 6'da yer almaktadır.

Tablo 6. Değişkenlere İlişskin Tanımlayıcı İstatistikler

\begin{tabular}{|c|c|c|}
\hline İstatistik & $\operatorname{lnX}$ & \\
\hline Mean & 3.20 & 1.16 \\
\hline Median & 3.23 & 1.17 \\
\hline Maximum & 3.32 & 1.20 \\
\hline Minimum & 3.00 & 1.09 \\
\hline Std. Dev. & 0.08 & 0.02 \\
\hline Skewness & -0.49 & -0.53 \\
\hline Jarque-Bera & 2.05 & 2.08 \\
\hline Toplam değişken sayısı & 29 & 29 \\
\hline
\end{tabular}

Tablo 6'da yer alan değişkenlere ilişkin tanımlayıcı istatistiklerden anlaşıldığı üzere doğal logaritma (ln) formuna dönüştürülen X ve Y değişkenlerinin oynaklık değerleri açısından birbirine benzemekle beraber, X değişkeninin oynaklığı, Y'den bir miktar yüksektir. Bu bilgiye göre; istihdamın, ihracata göre diğer ekonomik faktörlerden daha çok etkilendiği şeklinde bir yorum yapılabilir. Ayrıca hem X hem de Y değişkenleri sola çarpıktır ve bu durum iki değişken arasında uzun dönemli bir ilişki olabileceğine işaret etmektedir.

\subsection{Fourier Tabanlı Birim Kök Testleri}

Becker vd. (2006) tarafından geliştirilen FKPSS testi, Kwitkowski vd.(1992) tarafından geliştirilen KPSS tipi durağanlık testine dayanır. FKPSS birim kök testi, KPSS testinden farklı olarak yapısal kırılmaları da dikkate alan forma dönüştürülmüştür. Bu amaçla regresyonun deterministik bileşenlerini tahmin etmek için bir Fourier fonksiyonu kullanılmıştır. Böylece, bir dizinin u şeklindeki kırılmalarını ve düzgün kırılmalarını tespit ederek sabit testlerdeki doğrusal olmayan eğilimleri de hesaba katılmıştır.

$$
\begin{aligned}
& y=X_{t}^{\prime} \beta+Z_{t}^{\prime} y+r_{t}+\varepsilon_{t} \\
& r_{t}=r_{t-1}+u_{t} \\
& Z_{t}=\left[\sin \left(\frac{2 \pi k t}{T}\right), \cos \left(\frac{2 \pi k t}{T}\right)\right]^{\prime} \\
& y_{t}=\alpha_{0}+\beta_{1}+y_{1} \sin \left(\frac{2 \pi k t}{T}\right)+y_{2} \cos \left(\frac{2 \pi k t}{T}\right)+r_{t}+u_{t}
\end{aligned}
$$

Burada $\varepsilon$ t durağan hata terimini, $u$ t bağımsız - özdeş dağılımlı ve sabit varyanslı hata terimini, $\mathrm{k}$ frekans değerini ve $\mathrm{T}$ ise örneklem büyüklüğünü ifade etmektedir. H0: $\gamma 1=\gamma 2=0$ reddedilirse, serinin doğrusal olmayan bir bileşeni olmalıdır. Becker vd. (2006), güç kaybının çok sayıda $k$ ile ilişsili olduğunu ifade etmekte ve bu nedenle $k=1$ veya $k=2$ kullanılmamasını önermektedirler. Optimal frekansı $(k=1, \ldots ., 5)$ belirlerken her bir frekans için en küçük kalıntı kareler toplamını veren $k$ değeri seçilmelidir. 
Enders ve Lee (2012), Dickey-Fuller (1979) Birim Kök testini Fourier tipi bir yaklaşımla geliştirmişlerdir.

$$
y_{t}=\alpha(t)+\rho y_{t-1}+y t+\varepsilon_{t}
$$

Buna göre; $\alpha(\mathrm{t})$, t'nin deterministik fonksiyonunu, $\varepsilon_{t}$ ise $\left(\sigma_{\varepsilon}^{2}\right)$ varyansla durağan hata terimini ifade etmektedir. $\alpha(\mathrm{t})$ 'nin bilinmeyen ve doğrusal olmayan fonksiyonel formunu dönüştürmek amaciyla bir Fourier tipi regresyon önermişlerdir.

$$
\alpha_{t}=\alpha(0)+\sum_{k=1}^{n} \alpha_{k} \sin \left(\frac{2 \pi k t}{T}\right)+\sum_{k=1}^{n} \beta_{k} \cos \left(\frac{2 \pi k t}{T}\right) ; n \leq \frac{T}{2}
$$

Burada n; yaklaşıma dahil edilen frekans sayısını, k; frekans sayısını ve T ise gözlem sayısını ifade etmektedir. Bu denklem tahmin edilerek birim kökün boş hipotezi test edilmektedir. H0 test hipotezi kabul edildiğinde, birim kök vardır sonucuna ulaşılmaktadır.

\subsection{Asimetrik Nedensellik Testi}

Asimetrik nedensellik testi, Hatemi-J tarafından Granger ve Yoon (2002)'un eş bütünleşme testi için uyarladıkları yaklaşımdan hareketle geliştirilmiştir. Yazarın 2011 yılında yayınlanan çalışmasında genel hatları çizilen asimetrik nedensellik testi, 2012 yılında yayınlanan çalışmasıyla daha detaylı bir biçimde açıklanmıştır. Geliştirilen test, panel veri analizlerinde kullanıldığ 1 gibi zaman serisi analizleri için de kullanılabilmektedir. Burada ortaya konulan yaklaşımda; değişkenler arasındaki muhtemel nedensel bağıntıyı hem pozitif şoklar hem de negatif şoklar üzerinden açıklayabilme imkanı söz konusudur (Hatemi-J, 2011; 2012). Asimetrik nedensel bağıntının tespit edilmesinde, Eşitlik 7 ve Eşitlik 8 denklemleri; sırasıyla $y_{1, t}$ ve $y_{2, t}$ entegre verilerin rassal yürüyüş sürecinden hareketle türetilmektedir.

$$
\begin{aligned}
& y_{1, t}=y_{1 t-1}+\varepsilon_{1, t}=y_{1,0}+\sum_{i=1}^{t} \varepsilon_{1 i} \\
& y_{2, t}=y_{2 t-1}+\varepsilon_{2, t}=y_{2,0}+\sum_{i=1}^{t} \varepsilon_{1 i}
\end{aligned}
$$

Denkelmelerde $\mathrm{t}=1,2, \ldots, \mathrm{T}$ zaman boyutu, $y_{1,0}$ ve $y_{2,0}$ sabit terimler, $\varepsilon_{1 i}$ ve $\varepsilon_{2 i}$ hata terimlerini göstermektedir.

Pozitif şoklar ve negatif şoklar ise;

$\varepsilon_{1 i}^{+}=\max \left(\varepsilon_{1 i}, 0\right), \varepsilon_{2 i}^{+}=\max \left(\varepsilon_{2 i}, 0\right), \varepsilon_{1 i}^{-}=\min \left(\varepsilon_{1 i}, 0\right)$ ve $\varepsilon_{2 i}^{-}=\min \left(\varepsilon_{2 i}, 0\right)$ şeklindedir.

$\varepsilon_{1 i}=\varepsilon_{1 i}^{+}+\varepsilon_{1 i}^{-}$ve $\varepsilon_{2 i}=\varepsilon_{2 i}^{+}+\varepsilon_{2 i}^{-}$biçiminde gösterilirse, 9 ve 10 no.lu denklemler şu şekilde oluşturulur:

$$
\begin{gathered}
y_{1, t}=y_{1 t-1}+\varepsilon_{1, t}=y_{1,0}+\sum_{i=1}^{t} \varepsilon_{1 i}^{+}+\sum_{i=1}^{t} \varepsilon_{1 i}^{-} \\
y_{2, t}=y_{2 t-1}+\varepsilon_{2, t}=y_{2,0}+\sum_{i=1}^{t} \varepsilon_{2 i}^{+}+\sum_{i=1}^{t} \varepsilon_{1 i}^{-}
\end{gathered}
$$

$y_{1 t}^{+}=\sum_{i=1}^{t} \varepsilon_{1 i}^{+}, y_{1 t}^{-}=\sum_{i=1}^{t} \varepsilon_{1 i}^{-}, y_{2 t}^{+}=\sum_{i=1}^{t} \varepsilon_{2 i}^{+}$ve $y_{2 t}^{-}=\sum_{i=1}^{t} \varepsilon_{2 i}^{-}$denklemlerinden hareketle her bir değişken için pozitif ve negatif şoklar hesaplanabilmektedir.

11 no'lu denklem; pozitif şoklar ve negatif şokların toplam nedenselliğini elde etmek amacıyla $y_{t}^{+}=\left(y_{1 t}^{+}, y_{2 t}^{+}\right)$varsayımı ile p, VAR(p) vektör otoregresif modelden hareketle oluşturulmaktadır.

$$
y_{t}^{+}=v+A_{1} y_{t-1}^{t}+\cdots+A_{p} y_{t-1}^{+}+v_{t}^{+}
$$

Burada $y_{t}^{+} 2 \mathrm{x} 1$ vektörü, $v$ vektör düzeyi ve $v_{t}^{+} 2 \mathrm{x} 1$ ise hata terimlerinin vektörünü ifade etmektedir.

$\operatorname{Ar} 2 \times 2$ matrisinde gecikme sayısı $r(r=1, \ldots, p) p$ aşağıda yer alan 12 no.lu denklem yardımıyla hesaplanmaktadır:

$$
H J C=\ln \left|\widehat{\Omega}_{j}\right|+j\left(\frac{n^{2} \ln T+2 n^{2} \ln (\ln T)}{2 T}\right), J=0, \ldots, p
$$

Burada $\left|\widehat{\Omega}_{j}\right|$, VAR modelindeki j hatanın tahmini varyans-kovaryans matrisinin belirleyicisini, n; VAR modelindeki eşitlik sayısını ve T ise VAR modelindeki gözlem sayısını göstermektedir.

13 no. lu denklem; nedenselliğe ilişkin hipotezlerini test edilmesini sağlayan Wald testi istatistiklerinin hesaplanmasını göstermektedir. 


$$
\begin{gathered}
Y:=\left(y_{1}^{+}, \ldots, y_{T}^{+}\right)(n x T) \text { matris, } \\
Z_{t}:=\left[\begin{array}{c}
1 \\
y_{1}^{+} \\
y_{t-1}^{+} \\
\cdot \\
\cdot \\
y_{t-p+1}^{+}
\end{array}\right] \\
Z:=((1+n p) x 1) \text { matris, } \mathrm{t}=1, \ldots \mathrm{T} \\
\quad\left(Z_{0}, \ldots, Z_{T-1}\right)((1+n p) x T) \text { matris } \\
\delta:=\left(v_{1}^{+}, \ldots, v_{T}^{+}\right)(n x T) \text { matris }
\end{gathered}
$$

Pozitif ve negatif şoklar Wald testi istatistik sonuçlarına ve bootstrap dağılımına göre değerlendirilmektedir. Testin boş hipotezi "H0: değişkenler arasında nedensellik yoktur" biçimindedir.

\subsection{Ampirik Bulgular}

Fourier tabanlı non-lineer birim kök testleri olan FADF ve FKPSS birim kök testlerine ilişkin sonuçlar Tablo 7'de yer

\begin{tabular}{|c|c|c|c|c|c|c|c|c|c|c|}
\hline Değişken & \multicolumn{5}{|c|}{ FADF (Enders ve Lee, 2012) } & \multicolumn{5}{|c|}{ FKPSS (Becker vd. 2006) } \\
\hline Düzey & İst. & $\mathrm{L}$ & $\mathrm{K}$ & $\% 1$ & $\% 5$ & İst. & $\mathrm{L}$ & $\mathrm{K}$ & $\% 1$ & $\% 5$ \\
\hline $\ln \mathrm{X}$ & -3.810 & 1 & 1 & -4.95 & -4.35 & 0.290 & -- & 3 & 0.2103 & 0.1423 \\
\hline $\ln \mathrm{Y}$ & -3.819 & 1 & 1 & -4.95 & -4.35 & 0.293 & -- & 3 & 0.2103 & 0.1423 \\
\hline$\Delta$ (birinci fark & & & & & & & & & & \\
\hline $\ln \mathrm{X}$ & $-6.732 *$ & 1 & 3 & -4.45 & -3.78 & $0.0411 *$ & - & 3 & 0.2103 & 0.1423 \\
\hline $\ln \mathrm{Y}$ & $-6.800 *$ & 1 & 3 & -4.45 & -3.78 & $0.0425^{*}$ & --- & 3 & 0.2103 & 0.1423 \\
\hline
\end{tabular}
almaktadır. Türkiye Ekonomisi için ele alınan 1991-2019 dönemi için en az bir veya bilinmeyen sayıda yapısal kırılma olması ihtimali söz konusu testlerin tercih edilmesinde belirleyici olmuştur. Elde edilen bulgulara göre analize tabi tutulan her iki serinin de birinci farklarında durağan hale geldiği görülmektedir.

Tablo 7. Fourier Birim Kök Testi Sonuçları

Notlar: Maksimum Fourier sayısı 3 olarak seçilmiştir. Maksimum gecikme uzunluğu (1) Akaike ve SC bilgi kriterine göre belirlenmiştir. Her bir teste ait kritik değerler ilgili makalelerdeki tablo değerlerinden derlenmiştir. L: lag sayısını, K: Fourier sayısını göstermektedir. * \%1 anlamlılık düzeylerini göstermektedir. Constant and Trend değerler rapor edilmiştir.

Serilerin durağanlığını test ettikten sonra Toda-Yamamoto tabanlı Hatemi-J (2011) asimetrik nedensellik testi gerçekleştirilmiştir. Birim kök testlerine benzer biçimde non-lineer olan Hatemi-J (2011) asimetrik nedensellik testinde, serilerin düzeyde veya birinci farklarında durağan olması test için herhangi bir engel teşkil etmemektedir. Ayrıca söz konusu nedensellik testinde serilerin eşbütünleşik olmaları veya olmamaları da göz önünde bulundurulmamaktadır. Asimetrik nedensellik testi sonuçlarını gösteren bulgular Tablo 8'de yer almaktadır.

Tablo 8. Asimetrik Nedensellik Testi Sonuçları

\begin{tabular}{|c|c|c|c|c|c|c|}
\hline \multirow{2}{*}{ Nedensellik } & & & & \multicolumn{2}{|c|}{ Bootstrap Kritik Değerler } \\
\cline { 2 - 6 } & VAR(p) & MWALD & p-value & \%1 & \%5 & \%10 \\
\hline$Y+\neq>X+$ & 1 & $3.645^{*}$ & 0.056 & 0.000 & 0.000 & 0.000 \\
\hline$Y+\neq>X-$ & 1 & 0.000 & 0.985 & 15.446 & 6.696 \\
\hline$Y-\neq>X-$ & $4.326^{*}$ & 0.038 & 0.000 & 0.000 & 0.000 \\
\hline$Y-\neq>X+$ & 1 & 0.007 & 0.933 & 13.758 & 7.258 \\
\hline
\end{tabular}

Not: *\%1 istatistiki olarak anlamlı olduğunu göstermektedir. VAR'a dayalı maksimum gecike uzunluğu AIC ve SC’ye göre 1 olarak tespit edilmiştir. 1000 bootstrap ile çalışıldı. $\mathrm{Y} \neq>\mathrm{X}$; nedeni değildiri ifade eder. pmax:1 dir. pmax $+\mathrm{dmax}, 2$ dir.

Tablo 8'de yer alan asimetrik nedensellik testine ilişkin bulgular oldukça tutarlı sonuçlar sunmaktadır. Bu sonuçlara göre; "ihracata ilişkin pozitif şoklar istihdamda ortaya çıkan pozitif şokların nedeni değildir" ve "ihracata ilişkin negatif şoklar istihdamda ortaya çıkan negatif şokların nedeni değildir” hipotezleri reddedilmektedir. Buna göre ihracattaki artış veya azalışlar, istihdamda ortaya çıkan aynı yönlü değişimlerin nedeni olarak kabul edilmektedir.

\section{SONUC}

Sanayi devriminden sonra dünya ekonomisinde uluslararası ticaretin önemi her geçen gün artarak devam etmiştir. Merkantilist dönemlerden kalma alışkanlıklarla beraber ilk başlarda gelişmiş ülkeler için öncelik arz eden ihracatı artırma yarışına, 1980'li yıllardan itibaren gelişmekte olan ülkeler de katılmıştır. Gelişme yolunda olan pek çok ülkede olduğu gibi Türkiye'de de 24 Ocak 1980 kararlarıyla birlikte ithal ikameci sanayileşme politikaları yerini hızla ihracata yönelik sanayileşme politikalarına bırakmıştır. Bu dönüşümden sonra ihracat artışının istihdam başta olmak üzere çeşitli makro 
ekonomik göstergelere olan etkilerinin incelenmesi de akademik araştırmacılar açısından ilgi uyandırmıştır. Özellikle az gelişmiş ve gelişmekte olan ülkelerin gelişmiş ülkelere nispeten daha ciddi işsizlik problemiyle karşı karşıya olmaları, ihracatın istihdam üzerine olan etkilerini tespit etmek ve bunun sonucuna göre politika tercihinde bulunmak açısından önemlidir.

2020 yılı istatistiklerine göre Türkiye'nin gerçekleştirdiği yaklaşık olarak 170 milyar dolarlık ihracatın \%90'ından fazlası sanayi ürünlerini kapsamaktadır. Bu bağlamda çalışmada, Türkiye'nin sanayi sektörü ihracatının aynı sektördeki istihdama etkisinin ampirik olarak test edilmesi amaçlanmıştır. Analizde Dünya Bankası veri tabanından 1991-2019 dönemini kapsayan sanayi sektörü ihracatı ve istihdamına ilişkin veriler kullanılmıştır. Çalışmada ampirik yöntem olarak da Fourier tabanlı birim kök testleri ve Hatemi-J (2011) asimetrik nedensellik testi tercih edilmiştir. Çalışma, kullanılan veri seti, dönem aralığı ve ampirik yöntem olarak literatürde yer alan çalışmalardan farklılaşmakta ve bu açıdan literatüre katkıda bulunmaktadır. Analizden elde edilen ampirik bulgular, söz konusu dönemde Türkiye'de ihracattaki artışın istihdamın artmasına neden olduğunu, diğer yandan ihracattaki azalmanın da istihdamdaki azalmanın nedeni olduğunu işaret etmektedir. Bu sonuç ampirik literatürde yer alan çalışmaların çoğunda elde edilen "ihracat, istihdamı pozitif etkilemektedir" bulgusuyla örtüşmektedir.

Ampirik bulgular dışında ihracatın birim değer artışından ziyade miktar bazlı artmasının, üretimde artışa yol açacağı açıktır. Eğer miktar bazlı bu artış, emek verimliliğindeki ve teknolojideki gelişme dışında gerçekleşirse istihdamı artırması da mümkündür. Bu açıdan her ne kadar bu çalışmanın kapsamı dışında olsa da ihracat artışının verimlilik ve teknoloji ilişkisini irdelemek daha sağlıklı sonuçlara ulaşmak açısından yararlı olabilir. İhracat artışlarının verimlilik ve teknolojiyle olan etkileşimi yanı sıra ücretler üzerinde bıraktığı etkiler kanalıyla işgücü talebine olan etkilerini incelemek de başka bir çalışmanın konusu olabilir.

\section{KAYNAKÇA (REFERENCES)}

Abbey, E. N., Gyeke-Dako, A., Oduro, A. D., Turkson, F. E., \& Baffour, P. T. (2017). The Employment Generating Effects of Exporting: Firm level evidence of Micro, Small and Medium Enterprises (MSMEs) in Ghana. R4D Working Paper 2017/02.

Akkuş, G. (2014). The effects of trade and productivity on employment in the manufacturing industry of Turkey. İstanbul Üniversitesi İktisat Fakültesi Mecmuasi, 64(2), 1-44.

Akkuş, G. E. (2019). The Sectoral Employment Effects of International Trade and Productivity In The Manufacturing Industry of Turkey. European Trade Study Group (ETSG) Twenty-First Annual Conference (University of Bern-World Trade Institute) At: Bern-Switzerland, 12-14 September 2019.

Aktakaş, B. G., Mike, F., Aytun, C., \& Laleh, M. M. (2013). Sektörel İhracat-İstihdam İlişkisi: Türkiye Örneği (2004-2011). Çukurova Üniversitesi İktisadi ve İdari Bilimler Fakültesi Dergisi, 17(1), 37-50.

Altay, H., \& Yılmaz, A. (2016). Türkiye'de İhracat Artışlarının İstihdam Üzerindeki Etkisinin İncelenmesi. Finans Politik ve Ekonomik Yorumlar, 53(616), 75-86.

Altuntepe, N. (2018). Dış Ticaretin İstihdam Üzerine Etkilerinin Analizi: Karabük İli Örneği (2006: 1-2017: 12). Yönetim ve Ekonomi: Celal Bayar Üniversitesi İktisadi ve İdari Bilimler Fakültesi Dergisi, 25(3), 895-911. doi: 10.18657/yonveek.449910.

Aydiner-Avsar, N., \& Onaran, Ö. (2010). The determinants of employment: A sectoral analysis for Turkey. The Developing Economies, 48(2), 203231.

Ayhan, F. (2018). Türkiye ekonomisinde ihracat, ithalat ve istihdam düzeyi ilişkisinin uygulamalı analizi. Çankırı Karatekin Üniversitesi İktisadi ve İdari Bilimler Fakültesi Dergisi, 8(2), 115-135.

Becker, R., Enders, W., \& Lee, J. (2006). A stationarity test in the presence of an unknown number of smooth breaks. Journal of Time Series Analysis, 27(3), 381-409. https://doi.org/10.1111/j.1467-9892.2006.00478.x.

Chen, X., Cheng, L. K., Fung, K. C., Lau, L. J., Sung, Y. W., Zhu, K., Yang, C., Pei, J. \& Duan, Y. (2012). Domestic value added and employment generated by Chinese exports: A quantitative estimation. China Economic Review, 23(4), 850-864.

Çütcü, İ. \& Cenger, H. (2017). Türkiye'de Dış Ticaret ve İşsizlik Arasındaki İlişki: Yapısal Kırılmalı Zaman Serisi Analizi. III. Uluslararası Girișimcilik, İstihdam ve Kariyer Kongresi, Muğla: Türkiye, 12-15 Ekim 2017.

Dickey, D. A., \& Fuller, W. A. (1979). Distribution of the estimators for autoregressive time series with a unit root. Journal of the American statistical association, 74(366a), 427-431.

Dizaji, M., \& Badri, A. K. (2014). The Effect of Exports on Employment in Iran's Economy. Merit Research Journal of Art, Social Science and Humanities, 2(6), 081-088.

Enders, W., \& Lee, J. (2012). The flexible Fourier form and Dickey-Fuller type unit root tests. Economics Letters, 117(1), 196-199. https://doi.org/https://doi.org/10.1016/j.econlet.2012.04.081.

Ersin, İ., \& Ergeç, E. H. (2018). Harcama Bileşenleri Ve Sektörel İstihdam Arasindaki Nedensellik İlişkisi. Yönetim ve Ekonomi Araştırmaları Dergisi, 16(1), 161-180.

Feenstra, R. C., Ma, H., \& Xu, Y. (2019). US exports and employment. Journal of International Economics, 120, 46-58.

Fu, X., \& Balasubramanyam, V. N. (2005). Exports, foreign direct investment and employment: The case of China. World Economy, 28(4), 607-625.

Göçer, I., Mercan, M., \& Peker, O. (2013). Ihracat, Dogrudan Yabanci Yatirimlar ve Issizlik: Türkiye Örnegi/Export, Foreign Direct Investment and Unemployment: The Case of Turkey. Business and Economics Research Journal, 4(1), 103.

Görg, H. \& Görlich, D. (2011), Trade and Labour Market Outcomes in Germany, OECD Trade Policy Working Papers, No. 125, OECD Publishing. http://dx.doi.org/10.1787/5kg3nh94z5r8-en 
Granger, C. W., \& Yoon, G. (2002). Hidden cointegration. U of California, Economics Working Paper, (2002-02).

Greenaway, D., Hine, R. C., \& Wright, P. (1999). An empirical assessment of the impact of trade on employment in the United Kingdom. European Journal of Political Economy, 15(3), 485-500.

Gül, E., \& Kamacı, A. (2012). Dış Ticaretin İstihdam Üzerindeki Etkileri: Bir Panel Veri Analizi. Anadolu University Journal of Social Sciences, 12(4), 23-32.

Hatemi-J, A. (2011). Asymmetric panel causality tests with an application to the impact of fiscal policy on economic performance in Scandinavia. MPRA Paper No. 55527.

Hatemi-j, A. (2012). Asymmetric causality tests with an application. Empirical economics, 43(1), 447-456. https://doi.org/10.1007/s00181-011-0484$\mathrm{X}$.

Hisali, E. (2011). Trade, employment and gender: the case of Uganda. https://www.oecd.org/site/tadicite/48722379.pdf.

Hoekman, B. \& Winters, L. A. (2005). Trade and Employment: Stylized Facts and Research Findings. DESA Working Paper No. 7 , ST/ESA/2005/DWP/7.

Jansen, M. \& Lee, E. (2007). Trade and Employment: Challenges for Policy Research. Switzerland: International Labour Organization and World Trade Organization.

Karaçor, Z., \& Saraç, T. B. (2011). Dış ticaret ile sanayi sektörü istihdam oranı arasındaki kısa ve uzun dönem ilişkisi: Türkiye örneği (19632009). Yönetim ve Ekonomi: Celal Bayar Üniversitesi İktisadi ve İdari Bilimler Fakültesi Dergisi, 18(2), 181-194.

Kızılırmak, A. B. (2012). Türkiye Özel İmalat Sanayinde Dış Ticaretin İstihdam Üzerindeki Etkisi. Discussion Paper, (No. 2012/76).

Kien, N. T. (2015). Manufacturing exports and employment generation in Vietnam. Southeast Asian Journal of Economics, 3(2), 1-21.

Kien, T. N., \& Heo, Y. (2009). Impacts of trade liberalization on employment in Vietnam: a system generalized method of moments estimation. The Developing Economies, 47(1), 81-103.

Kutlina-Dimitrova, Z., Rueda-Cantuche, J. M., Amores, A., \& Román, V. (2018). How important are EU exports for jobs in the EU? (No. 2018-4). Directorate General for Trade, European Commission.

Kwiatkowski, D., Phillips, P. C., Schmidt, P., \& Shin, Y. (1992). Testing the null hypothesis of stationarity against the alternative of a unit root: How sure are we that economic time series have a unit root?. Journal of econometrics, 54(1-3), 159-178.

Leichenko, R. M. (2000). Exports, employment, and production: A causal assessment of US states and regions. Economic Geography, 76(4), 303-325.

Polat, O., Uslu, E. E., \& Aydemir, C. (2011). İmalat sanayinde diş ticaret ve istihdamın panel veri analizi. Business and Economics Research Journal, 2(3), 161-171.

Sasahara, A. (2019). Explaining the employment effect of exports: value-added content matters. Journal of the Japanese and International Economies, 52, 1-21.

Tandoğan, D. (2019). The Impact of Export on Employment: Panel Data Analysis for Regional Base in Turkey. Bingöl Üniversitesi Sosyal Bilimler Enstitüsü Dergisi (BUSBED), 9(18), 799-814.

Thompson, G., Murray, T., \& Jomini, P. (2012). Trade, employment and structural change: The Australian experience (No. 137). OECD Publishing, $113-143$.

Tuhin, R. (2015). Impact of international trade on employment: Evidence from Australian manufacturing industries. Office of the Chief Economist research papers, 2(2015), 1-29.

Van Ha, H., \& Tran, T. Q. (2017). International trade and employment: A quantile regression approach. Journal of Economic Integration, 32(3), 531557. http://dx.doi.org/10.11130/jei.2017.32.3.531

Whang, U. (2019). Exports and job creation in South Korea: industry-level analysis. Journal of Korea Trade, 23(1), 2-18.

Yildiz, N., \& Akdugan, U. (2014). Long Term-Short Term Analyse Between Foreign Trade, Growth and Employment in Turkish Economy: 19232013. IIB International Refereed Academic Social Sciences Journal, 5(15), 247. 
